\title{
Assessment of Acute Abdomen among Patients attending Government General Hospital of Kakinada: A Prospective Study
}

\author{
V. Durgaprasad Mutyala ${ }^{1}$, D. Dhanya Charitha ${ }^{2}$ \\ ${ }^{1}$ Junior Resident, Department of General Surgery, GGH, Kakinada, 2Junior Resident, Department of General Surgery, GGH, \\ Kakinada, Andhra Pradesh, India
}

Corresponding author: Dr R . Mahalakshmi M.S, Professor of Surgery, Department of General Surgery, Kakinada, , Andhra Pradesh, India

DOI: http://dx.doi.org/10.21276/ijcmsr.2019.4.2.12

How to cite this article: V. Durgaprasad Mutyala, D. Dhanya Charitha. Assessment of acute abdomen among patients attending government general hospital of Kakinada: a prospective study. International Journal of Contemporary Medicine Surgery and Radiology. 2019;4(2):B51-B55.

\section{A B S T R A C T}

Introduction: Acute abdomen refers to the clinical condition in which an acute change in the condition of the intraabdominal organ, usually related to inflamed or infected, demands immediate and accurate diagnosis with acute abdominal pain present for less than 6-8 hours. Acute appendicitis is more common in children whereas biliary disease, colonic diverticulosis, and intestinal infarction occur more commonly in the elderly. Therefore, the aim of this present study was to assess the incidence of various causes of non-traumatic acute abdomen and to study the clinical features and causes of non-traumatic acute abdomen.

Material and methods: The present study was a prospective study where all the patients were admitted through surgical OP/Casualty in General Government Hospital, Kakinada from August 2016 to August 2018 with acute abdominal pain. Total 180 were selected and they were examined clinically and evaluated with complete blood picture renal function test, liver function test, ultrasound abdomen X-ray chest, X-ray erect abdomen and CT abdomen accordingly in relevance with clinical diagnosis.

Results: The males outnumbered females in the ratio of 2:1. The maximum number of cases 55 occurred in the age group of 21-30 years. The common cause of an acute abdomen was acute appendicitis in 101 cases. All patients underwent emergency laparotomy and were managed accordingly. There was a significant post-operative wound infection in 23 cases. There was mortality in 18 out of 180 cases. Delayed presentation and delayed intervention increased the mortality and morbidity.

Conclusion: Acute appendicitis was the most common condition seen in this study.

Keywords: Acute Abdomen, Appendicitis, X-ray Chest, Abdominal Pain

\section{INTRODUCTION}

Hippocrates observations of manifestations of acute abdominal conditions have been a masterpiece about life and its meaning. Among the conditions that relate peculiarly to the small intestine is intestinal obstruction recognized as early as eighth century BC. At that time, Sushrutha recommended that obstruction is treated by incision of the intestine, replacement of organs after moistening them with honey and butter and sewing up of the intestine. Acute abdomen refers to the clinical condition in which an acute change in the condition of the intra-abdominal organ, usually related to inflamed or infected, demands immediate and accurate diagnosis with acute abdominal pain present for less than 6-8 hours. ${ }^{1,2}$

The challenging and most fascinating subject in surgery is the study of the acute abdomen. It constitutes about $5-10 \%$ of all emergency department visits. ${ }^{1}$ Cope in 1921 wrote that 'the majority of severe abdominal pain which ensure in patients who have been previously fairly well and which lasts as long as 6hours are caused by conditions of surgical importance. ${ }^{3}$

Success in the treatment of acute abdomen depends mostly on early diagnosis with early intervention and proper postoperative care. Sir Henle's aphorism is that in acute abdominal emergencies, the difference between the best and worst surgery is infinitely less than between early and late surgery and greatest sacrifice is the sacrifice of time. ${ }^{4}$

The acute abdominal pain generates a large number of hospital visits and may affect all age groups and both sexes all socioeconomic group. Acute appendicitis is more common in children whereas biliary disease, colonic diverticulosis, and intestinal infarction occur more commonly in the elderly. The case history remains one of the most useful tools in the diagnosis of gastrointestinal disease and art of physical examination is also of great importance in the diagnosis of abdominal pain. ${ }^{5}$ 
A surgeon should be able to recognize the physiologic difference between visceral, somatic and referred pain to understand the clinical significance of anorexia, nausea, and vomiting to correlate interrelationships of symptoms (i.e., pain and vomiting processes). The peritoneal cavity is a potential space, lined by visceral and parietal peritoneum. Each of these two surfaces has distinctive pain pathways and characteristics. The third type of pain, called referred pain, causes a sensation at a distant site from the affected organ. This type of pain sometimes helps, but often hinders and confuses the diagnosis. ${ }^{6}$

The peritoneal cavity is a potential space, lined by visceral and parietal peritoneum. Each of these two surfaces has distinctive pain pathways and characteristics. The third type of pain, called referred pain, causes a sensation at a distant site from the affected organ. This type of pain sometimes helps, but often hinders and confuses the diagnosis. ${ }^{7}$

The appearance of the patient will frequently give some general clues as to the severity of the illness, look for toxicity, colour of skin, cyanosis of lips or mucosa, distention of veins in neck or trunk, respiratory rate, and effort, the position of limb, etc. The position of patients may provide a clue. The patients with renal or biliary colic are restless and been described as 'climbing the wall with pain.' In contrast, patients with peritoneal irritation prefer to be immobile because movement increases discomfort. Small bowel obstruction produces intermittent cramping pain, and the patient will 'Double up' at intervals. ${ }^{8}$

The acute abdominal pain generates a large number of hospital visits and may affect all age groups and both sexes all socioeconomic group. Acute appendicitis is more common in children whereas biliary disease, colonic diverticulosis, and intestinal infarction occur more commonly in the elderly. The case history remains one of the most useful tools in the diagnosis of gastrointestinal disease and art of physical examination is also of great importance in the diagnosis of abdominal pain. ${ }^{9}$ Therefore, the aim of the present study is to assess the incidence of various causes of non-traumatic acute abdomen and to study the clinical features and causes of non-traumatic acute abdomen.

\section{MATERIAL AND METHODS}

The present study was a prospective study where all the patients were admitted through surgical OP/Casualty in General Government Hospital, Kakinada from August 2016 to August 2018 with acute abdominal pain. Total 180 were selected and they were examined clinically and evaluated with complete blood picture renal function test, liver function test, ultrasound abdomen $\mathrm{X}$-ray chest, $\mathrm{X}$-ray erect abdomen and $\mathrm{CT}$ abdomen accordingly in relevance with clinical diagnosis. The patients who were surgically managed and were over 15 years of age were selected with patients coming to casualty. Patients with Traumatic acute abdomen were excluded with age under 15 years. Obstetric and gynaecological cases were excluded from this study. Patient managed conservatively, and patients who refused surgery were also not selected for the study.

Patients who need surgical management were prepared for surgery accordingly with relevant investigations like ECG,
ABG, Sr. Electrolytes, 2D Echocardiography and were taken for the surgery. All patients underwent laparotomy were compared with intraoperative diagnosis, the post-op period of all patients were followed. The etiology, diagnosis, outcome was analyzed; all cases were followed for a period of 3 months after the discharge.

\section{STATISTICAL ANALYSIS}

The data was entered in the excel spread sheet and statistical analysis was performed using SPSS 19 version. The descriptive analysis was calculated using percentage.

\section{RESULTS}

In the present study, Table no. 1 shows that the majority of the subjects were from the age group 21-30 years (30\%) followed by less than 20 years $(22.2 \%)$ and $31-40$ years (15.6\%). The least subjects were from the age group of 51-60 years $(8.9 \%)$ followed by $41-50$ years $(13.3 \%)$ and more than 60 years (9.4).

Table no. 2 shows that the majority of the subjects were males i.e. $65.5 \%$ and about $34.4 \%$ of them were found to be females. Out of 180 cases, the etiology of acute abdomen was found to be acute appendicitis i.e. 101 cases in the ratio of 2:1. Intestinal obstruction was also found in 41 cases with a ratio of 1:1 followed by HVP in 34 cases with a ratio of 10:1 and rupture liver abscess in 4 cases only. Males were most commonly seen with all the etiologies i.e. 118 cases and about 62 cases of female were found to be affected with all the etiologies of acute abdomen (Table no. 3).

In the current study, table no. 4 shows the distribution of data among the study subjects in relation to investigation of acute abdomen. It was found that $\mathrm{x}$-ray erect abdomen was taken in all the cases suspicious of perforation and obstruction, gas under diaphragm is present in 24 cases, and 6 cases were negative for the test, in obstruction multiple air-fluid levels were present in 37 cases, and 5 cases have only dilated bowel loops. USG abdomen was performed in all the cases of acute abdomen, 22 cases out of 101 cases were inconclusive having only probe tenderness, 4 out of 4 cases of rupture liver abscess were positive and diagnosed in USG.

\begin{tabular}{|l|c|c|c|c|}
\hline Age & No. of Patients & Percentage & Males & Females \\
\hline$<20$ & 40 & 22.2 & 22 & 18 \\
\hline $21-30$ & 55 & 30.56 & 42 & 13 \\
\hline $31-40$ & 28 & 15.6 & 18 & 10 \\
\hline $41-50$ & 24 & 13.3 & 16 & 8 \\
\hline $51-60$ & 16 & 8.9 & 10 & 6 \\
\hline$>60$ & 17 & 9.4 & 10 & 7 \\
\hline Total & 180 & 100 & 118 & 62 \\
\hline \multicolumn{5}{|c|}{ Table-1: Shows the distribution of data based on age group } \\
among the study subjects \\
\hline
\end{tabular}

\begin{tabular}{|l|c|c|}
\hline Gender & No. of Cases & Percentage \\
\hline Male & 118 & 65.5 \\
\hline Female & 62 & 34.4 \\
\hline Total & 180 & $100 \%$ \\
\hline \multicolumn{2}{|c|}{ Table-2: Shows the distribution of data based on gender } \\
among the study subjects \\
\hline
\end{tabular}




\begin{tabular}{|c|c|c|c|c|}
\hline \multicolumn{2}{|l|}{ Etiology } & No.of Cases & Wound Infection & Mortality \\
\hline \multicolumn{2}{|l|}{ Appendicitis } & 101 & 12 & - \\
\hline \multirow[t]{6}{*}{ HVP } & Gastric & 05 & 0 & 1 \\
\hline & Duodenal & 18 & 4 & 7 \\
\hline & Appendicular & 6 & 1 & 0 \\
\hline & Ileal & 2 & 2 & 0 \\
\hline & Sigmoid perforation & 1 & 0 & 1 \\
\hline & Jejunal & 1 & 1 & \\
\hline \multirow[t]{6}{*}{ Intestinal Obstruction } & Sigmoid Volvulus & 9 & 0 & 2 \\
\hline & Adhesions & 6 & 0 & 0 \\
\hline & Hernia & 19 & 1 & 2 \\
\hline & Mesenteric ischaemia & 4 & 1 & 2 \\
\hline & Malignancy & 2 & 0 & 2 \\
\hline & Others & 3 & 0 & 0 \\
\hline \multicolumn{2}{|l|}{ Ruptured liver abscess } & 4 & 1 & 1 \\
\hline \multicolumn{2}{|l|}{ Total } & 180 & 23 & 18 \\
\hline
\end{tabular}

\begin{tabular}{|c|c|c|c|c|c|c|}
\hline \multicolumn{2}{|l|}{ Etiology } & \multirow[t]{2}{*}{ No.of Cases } & \multicolumn{2}{|l|}{ X-ray errect } & \multicolumn{2}{|c|}{ USG } \\
\hline & & & Gas Under Diaphra GM & Maf levels & $+V E$ & -VE \\
\hline \multicolumn{2}{|l|}{ Appendicitis } & 101 & - & - & 81 & 20 \\
\hline \multirow[t]{6}{*}{ HVP } & Gastric & 5 & 5 & - & - & - \\
\hline & Duodenal & 18 & 12 & - & - & - \\
\hline & Appendicular & 6 & 3 & - & 4 & 2 \\
\hline & Ileal & 2 & 1 & - & - & 2 \\
\hline & Jejunum & 1 & 1 & - & - & - \\
\hline & Sigmoid perforation & 1 & 1 & - & - & - \\
\hline \multirow[t]{6}{*}{ Intestinal obstruction } & Sigmoid Volvulus & 8 & - & 8 & - & - \\
\hline & Adhesions & 6 & - & 6 & - & - \\
\hline & Hernia & 19 & - & 16 & - & - \\
\hline & Mesenteric ischaemia & 4 & - & 4 & - & - \\
\hline & Malignancy & 2 & - & 2 & 2 & - \\
\hline & Others & 3 & - & 1 & - & - \\
\hline \multicolumn{2}{|l|}{ Ruptured liver abscess } & 4 & - & 2 & 4 & - \\
\hline
\end{tabular}

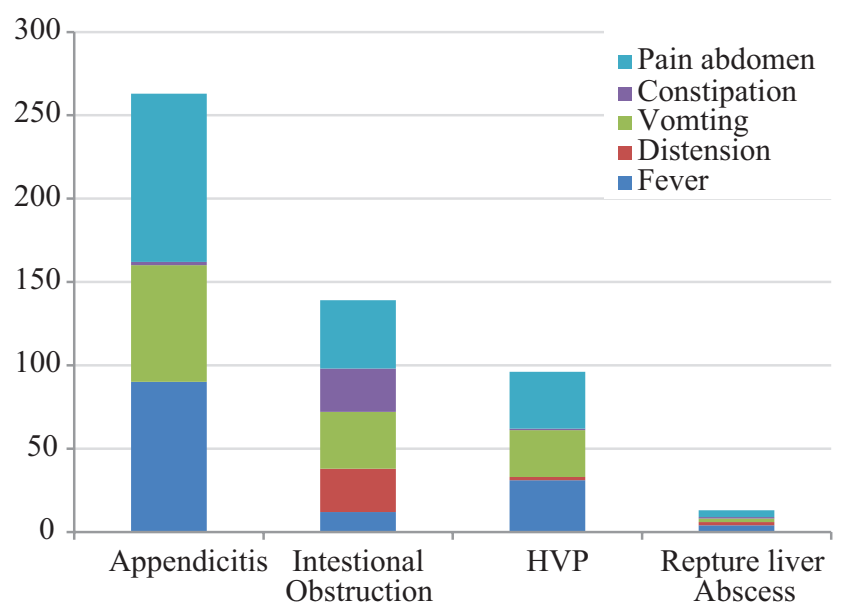

Graph-1: Shows the distribution of data based on the symptoms of acute abdomen among the study subjects

Graph no. 1 shows that in the present study, pain in abdomen was present in all the cases, followed by fever and vomiting, constipation and distention were also associated with abdominal pain. Graph no. 2 shows that in the present study

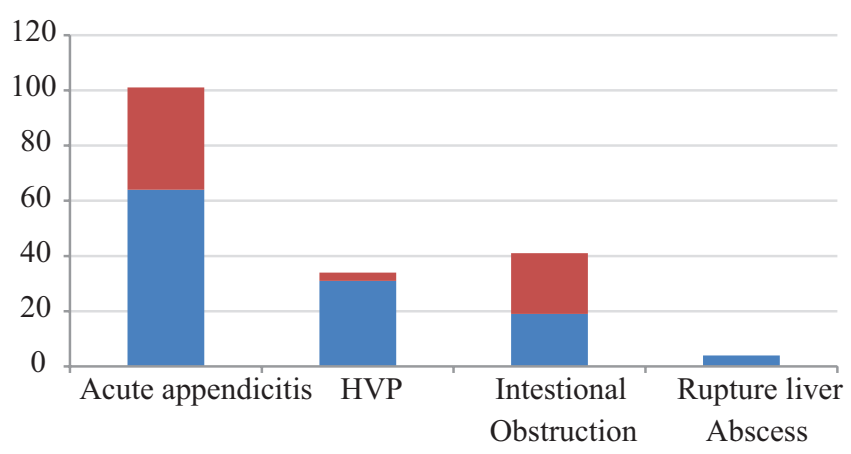

Graph-2: Shows the distribution of data according to the etiology of acute abdomen among the study subjects

appendicitis was the commonest cause of acute abdomen with 101 cases (56.1\%) followed by intestinal obstruction in 42 cases $(23.3 \%)$, followed by hollow viscous perforation in 33 cases (18.3\%) and rupture liver abscess in 4 cases (2.2\%).

\section{DISCUSSION}

Acute appendicitis is one of the most common causes of acute abdomen in the present study with 101 cases. The maximum 
incidence of acute appendicitis was seen between 21-30 years of age group, which is about $44.5 \%$ with 45 cases. In a study, done by Bhatnagar et al it was found that the incidence was maximum in the age group of $21-30$ years, with $44 \%$, which is in concordance with the present study. ${ }^{10}$

Perforation of hollow viscous is one of the most frequent surgical emergency. The following were the observations made from the study of 34 patients of hollow viscous perforation in adults. Age distribution in present study was found to be 21years to 56 years; maximum incidence of hollow viscous perforation was seen between the age group of 20 to 40 years which were about 18 cases contributing $52.35 \%$. The study conducted by Dandapat et al found that maximum incidence was seen between the age group of 21 years to 40 years with 130 cases and $62 \%$ and these findings are in concordance with the results of the present study.

The most likely persons to have a hollow viscous perforation were healthy middle-aged adults. In the present study, males were found to be more than females and belong to an economically productive age group of $21-40$ years. In the present study, the ratio of males to females is 10:1. In a study conducted by Dandapat et al it was found that out of 340 cases, 304 were males, and 36 cases were females with M: F ratio of $8.4: 1$ and these findings were found to be similar to the present study. ${ }^{11}$

In the present study, the frequent site of perforation was duodenal followed by appendicular and gastric perforation which included ileum, jejunum and sigmoid. The present study encompasses a data of pattern perforation of hollow viscous diagnosed by clinical examination confirmed by various investigations available. In the study conducted by DCM Rao et al it was revealed that out of 46 cases, the most common perforation was duodenal perforation with 20 cases (43\%) followed by ileal 15 cases (39\%), gastric 6 cases (13\%) and other 2 cases (4\%) and these findings are in concordance with the present study. ${ }^{12}$

The highest incidence of duodenal perforation was might be due to incomplete treatment of the H. Pylori, even triple therapy was not found to be helpful. Alcoholism, smoking and NSAID abuse also played a significant role in duodenal perforation, size of duodenal perforations rarely of size more than $1 \mathrm{~cm}$. Gastric perforations were relatively less frequent; it followed gastric ulcer in the present study. Appendicular perforation is usually a complication of appendicitis usually with pain in the in right lower quadrant of the abdomen, after perforation, it has been walled off by surrounding intraabdominal structures and perforations most often happens when patient referred from small hospitals after the delay in diagnosis. ${ }^{13}$

Approximately $100 \%$ of cases had pain abdomen, majority of patients in the present study exhibited positive findings on investigations such as evidence of pneumoperitoneum in $\mathrm{x}$-ray chest or erect abdomen. A study done by Memon et al noted that investigations such as erect $\mathrm{x}$-ray abdomen have doubtful reliability, supporting the present study in respect to investigations other investigators have also reported a decisive role in reporting $50 \%$ of cases had pneumoperitoneum. In a study done by Bali et al it was noted that $79 \%$ of patients had pneumoperitoneum on chest x-ray. In the present study, perforations involved the proximal part of gastrointestinal tract; this observation was in contrast to views of Memon et al, Qureshi et al and the Dorairajan et al. ${ }^{14,15,16,17}$

The overall mortality due to perforation peritonitis in the present study was $26.4 \%$ with 9 deaths. In a study done by Dandapat et al it was found that the mortality was $10.5 \%$, various comparative studies have observed the overall mortality range from $6-27 \%$. The main cause of death in the present study was wound infection and septicemia and electrolyte imbalance, so early surgical intervention curtails further contaminations.

A total of $14.2 \%$ of cases attributed to adhesions, Shaiksufian et al. reported adhesions as a cause of intestinal obstruction in $32.5 \%$ of cases. A total number of 19 cases, of intestinal obstruction, are related to obstructed hernia in this study of 42 cases contributing to $42.8 \%$ of cases. In a study conducted by Budhiraja revealed that the etiology for acute intestinal obstruction secondary to obstructed hernia was found to be $33 \%$. Volvulus constituted for about 8 cases out of these, all cases were sigmoid volvulus, and $18.2 \%$ of cases of intestinal obstruction were due to volvulus, gangrene of sigmoid volvulus was found in $50 \%$ of cases in the present study but in the study done by Sarkar et al it was revealed to be $31 \%$ and these findings are not inconsistent with the present study. ${ }^{18,19,20}$

Small bowel obstruction is more often due to adhesions and hernia while large bowel obstruction is more often due to volvulus and malignancy. Maximum presenting symptoms in the present study was pain abdomen (100\%), vomiting $81 \%$, distension of abdomen (61\%), constipation (64.2\%). A study done by Espalwe et al found that incidence of pain in abdomen was $100 \%$ vomiting was also $100 \%$ followed by constipation in $70 \%$ of cases and distention in $92 \%$ of the cases. The most common surgical procedure performed in cases of intestinal obstruction was hernia reduction and repair which included inguinal, femoral, paraumbilical, next common procedure was resection and anastomosis of sigmoid volvulus and mesenteric ischemia and strangulated hernia followed by adhesiolysis. Infection was the main cause of morbidity and was seen in $25 \%$ mortality was $21.4 \%$ seen patients with strangulation and increased age and sepsis. ${ }^{21}$

\section{CONCLUSION}

Acute appendicitis was the most common condition seen in the present study. The patient who presented late, undergoing delayed surgery increased the morbidity and mortality. From the study, it can be concluded that early presentation, early diagnosis, good preoperative and postoperative care was essential for all the cases of the acute abdomen to reduce mortality.

\section{REFERENCES}

1. K Rajyalakshmi, Koram Ananya Jyothi. A study on aetiology of abdominal pain in females of repproductive age group in rural area of Srikakulam District, Andhra Pradesh. International Journal of Contemporary Medical Research 2017; 4 (9):1991-1994.

2. P. Vanathi, B. Aquinas, V. Meenakshi Sundaram. Study on surgical management of acute intestinal obstruction 
in adults. International Journal of Contemporary Medical Research 2017; 4(9):1851-1855.

3. Mutharaju KR. An Analysis of Interventions in Acute Abdomen and its Post-Operative Complications. International Journal of Contemporary Medical Research 2017; 4(3):704-706.

4. Brown SP. The peritoneum, the mesentery, and the greater omentum and acute abdomen. In: Burnand KG, Young AE. The new airds companion in surgical studies. Churchill living stone Great Britain 1998; 693-762.

5. Anand Thawait, Sankalp Dwivedi, Manisha Bhatt, Karan Bakhshish, Amit Mittal. Role of early laparoscopy in diagnosis of acute abdominal pain. International Journal of Contemporary Medical Research 2017; 4(7):1568-1574.

6. Britton J. The acute abdomen In Morris PJ, Wood WC. Oxford textbook of surgery Oxford Press, New York. 2000; 1823-1841.

7. Doherty GM, Boey JH. The acute abdomen In Way LW, Doherty GM. Current surgical diagnosis and treatment 11th edition McGraw Hill USA 1994:503-516.

8. Kaleem Ahmad, Rishav Kumar Jain, Ashok Yadav, Shilpa Vahikar. Role of ultrasonography in diagnosis of acute abdomen (non-gynaecological causes). International Journal of Contemporary Medicine Surgery and Radiology. 2018; 3(3):C121-C125.

9. Carter DC. Acute abdomen In Shearman DJC, Finlayson N,Camilleri M. Disease of the gastrointestinal tract and liver. 511-537.

10. Bhatnagar et al. Acute appendicitis a clinicopathological study of 100 cases. Indian J Surg 1978; 40.

11. Dandapat $\mathrm{MC}$ et al. Gastrointestinal perforation review of 340 cases. Indian J Surg1991; 53(5):189-193.

12. Rao CDM, Mathur D, Anand RM. Gastrointestinal perforation - A study of 46cases. Indian J Surg 1984; 94-96.

13. Britton J. The acute abdomen In Morris PJ, Wood WC. Oxford textbook of surgery Oxford Press, New York. 2000; 1823-1841.

14. Memom AA, Siddiqui FG, Abro AH. An audit of secondary peritonitis at a tertiary care university hospital of Sindh. Pakistan World J Emerg Surg. 2012, 7(1):6-10.

15. Bali RS, Verma S, Agarwal PN, Singh R, Talwar N. Perforation peritonitis and the developing world. ISRN Surg. 2014; Article ID 105492.

16. Qureshi AM, Zafar A, Saees K, Quddus A. Predictive power of Mannheim peritonitis index. J Coll Physicians Surg Pak. 2005; 15(11):693-696.

17. Dorairajan et al Peritonitis in India, A decade experience Tropical gastro enterology, 1995; 16:13.

18. Sufian S et al. Intestinal obstruction. Am J Surg 1975; 130.

19. Budhiraja SN et al. Acute intestinal obstruction in Pondicherry. Indian J Surg 1976:38(4):3,111.

20. Sarkar PK, Sarkar V. primary resection and anastomoses associated with rectal stretching (MRS) for treatment of acute sigmoid volvulus. IJS 2000; 62(2): 122-124.

21. Palwe ES. Post-operative intestinal obstruction. Indian J Surg 1988; 284-286.

\section{Source of Support: Nil; Conflict of Interest: None}

Submitted: 10-04-2019; Accepted: 01-05-2019; Published online: 22-05-2019 